\title{
Effects Of Early-Stage Blood Pressure Variability On The Functional Outcome In Acute Ischemic Stroke Patients With Symptomatic Intracranial Arterial Stenosis Or Occlusion Receiving Intravenous Thrombolysis
}

\author{
Mian-Xuan Yao \\ Dongguan People's Hospital \\ Dong-Hai Qiu \\ Dongguan People's Hospital \\ Jiang-Hao Zhao \\ Dongguan People's Hospital \\ Han-Peng Yin \\ Dongguan People's Hospital \\ Yong-Lin Liu ( $\nabla$ ly_twins@126.com ) \\ Dongguan People's Hospital \\ Yang-Kun Chen \\ Dongguan People's Hospital
}

\section{Research Article}

Keywords: Blood pressure variability, Symptomatic intracranial artery stenosis or occlusion, Intravenous thrombolysis, Acute ischemic stroke, Prognosis

Posted Date: June 22nd, 2021

DOl: https://doi.org/10.21203/rs.3.rs-598417/v1

License: (a) (1) This work is licensed under a Creative Commons Attribution 4.0 International License. Read Full License 


\section{Abstract}

Background: Studies exploring on the relationship between blood pressure fluctuations and outcome in acute ischemic stroke (AIS) patients treated with intravenous thrombolysis (IVT) are limited. We aimed to investigate the influence of blood pressure variability (BPV) during the first 24 hours after IVT on neurological deterioration (END) and 3-month outcome after IVT in patients with symptomatic intracranial arterial stenosis or occlusion (SIASO).

Methods: Clinical data from consecutive AIS patients with SIASO who received IVT were retrospectively analyzed. The hourly systolic BP of all patients were recorded during the first 24 hours following IVT. We calculated three syslolic BPV parameters including coefficient of variability (CV), standard deviation of mean BP (SD) and successive variation (SV). The SV was categorized into four grades based on quartiles. The END was defined as neurological deterioration with an increase in the National Institutes of Health Stroke Scale (NIHSS) score $\geq 4$ points within the first 72 hours after admission. Follow-ups was performed at 90 days after onset were performed, and favorable and poor outcome were defined as a modified Rankin Scale scores of $\leq 1$ or $\geq 2$, respectively.

Results: A total of 110 patients were included, with a mean age of $62.0 \pm 12.5$ years. 86 patients $(78.2 \%)$ were male. Twenty patients (18.2\%) experienced END, and 37 patients (33.6\%) had a favorable outcome. Compared with patients with in the poor outcome group, age ([64.8 \pm 10.9$]$ vs [56.7 \pm 13.8$])$, NIHSS on admission (11.0 [7.0 -16.0] vs 6.0 [3.5 - 9.0]), SV ([14.5 \pm 4.3$]$ vs $[11.8 \pm 3.2])$ and SD $([12.7 \pm 3.8]$ vs $[10.9 \pm 3.3])$ were lower in the favorable outcome group (all $p<0.05)$. No BPV parameters were associated with END. In the multivariable logistic regression analysis, compared with the lowest SV (SV<25\% quartile), $\mathrm{SV}_{50 \%-75 \%}$ (odds rato $[\mathrm{OR}]=4.449,95 \%$ confidence interval $\left.[\mathrm{Cl}]=1.231-16.075, \mathrm{p}=0.023\right)$ and $\mathrm{SV}_{>75 \%}(\mathrm{OR}=8.676,95 \% \mathrm{Cl}=$ 1.892-39.775, $p=0.005$ ) were significantly associated with poor outcome at 3 months.

Conclusions: SV had a negative relationship with the 3-month outcome in AIS patients with SIASO treated with IVT, indicating that BPV may affect the outcome of AIS.

\section{Background}

Globally, stroke is the second most common cause of death and the third most common disabling disease [1, 2]. Intravenous thrombolysis therapy (IVT) can significantly improve functional outcomes. However, previous studies have reported that IVT outcomes are associated with various factors [3-5], including age [6], Trial of Org 10172 in Acute Stroke Treatment (TOAST) classification [7-10], National Institutes of Health Stroke Scale (NIHSS) score on admission, and systolic blood pressure (SBP) on admission [11].

Symptomatic intracranial arterial stenosis or occlusion (SIASO) is an important risk factor for poor prognosis after acute ischemic stroke (AIS) [12, 13]. The Warfarin-Aspirin Symptomatic Intracranial Disease trial revealed that $44 \%$ of strokes in the territory of the intracranial artery were disabling, whereas just $31 \%$ of strokes outside of this territory were disabling [12].

Blood pressure variability (BPV) is the fluctuation of BP over a certain period of time. Blood pressure (BP) fluctuations are a process of constant adjustment in response to various environmental factors, both inside and outside the body, to better adapt to the needs of the body. Fluctuations in BP are the result of the joint action of a range of factors, such as nerve and humoral regulation. Recently, higher BPV within 24 hours after stroke was reported to be associated with poor outcome after IVT [11, 1417]. However, SIASO, which is significantly associated with poor outcome after AIS [7-10, 12, 13], was not investigated separately in these previous studies. In the present study, we aimed to explore the influence of BPV during the first 24 hours after IVT on neurological deterioration (END) and 3-month outcome in patients who had SIASO and received IVT.

\section{Methods}

\section{Patient selection}


Patients with AIS who were treated with recombinant tissue plasminogen activator (r-tPA) IVT and admitted to Dongguan People's Hospital between 1 January 2017 and 31 December 2019 were consecutively recruited. The inclusion criteria were as follows: (1) aged > 18 years; (2) AIS was confirmed by magnetic resonance imaging (MRI) on admission; (3) SIASO was confirmed by three-dimensional time-of-flight magnetic resonance angiography; (4) onset of stroke symptoms was within 4.5 hours of treatment with r-tPA; (5) clinical features and BP were recorded at baseline and then hourly for 24 hours after IVT; (6) prestroke modified Rankin Scale (mRS) score $\leq 1$; and (7) follow-up by face-to-face consultation or by phone at 3 months, with complete documentation. The exclusion criteria were as follows: (1) additional endovascular therapy after IVT; (2) incomplete clinical data or lost to follow-up; and (3) permanent or temporary contraindication for MRI. This study was approved by the ethics committee of Dongguan People's Hospital (approval number: KYKT2018-002). The study was considered exempt from requiring informed consent from patients because of its retrospective nature.

\section{Data collection}

Demographic data including age, sex, and a history of hypertension, diabetes mellitus, smoking, atrial fibrillation, and previous stroke were collected. Stroke subtypes were classified according to the TOAST criteria [18], and the NIHSS on admission, onsetto-treatment time, SBP on admission, and hourly SBP for 24 hours after IVT were also collected.

\section{Definition of BPV}

The hourly SBPs of all patients were recorded during the first 24 hours after IVT using a cuff-type BP monitor. According to the guidelines [19], intravenous urapidil was administered to reduce BP levels to $<185 / 110 \mathrm{mmHg}$ just before r-tPA administration, and to maintain BP levels at $<180 / 105 \mathrm{mmHg}$ during the first 24 hours after IVT. The BPV was calculated using the following equation [14]:

(1) Standard deviation of mean BP (SD): $\sqrt{1 /(n-1) \quad \sum_{i=1}^{(n-1)}\left(\mathrm{BP}_{i}-\mathrm{BP}_{\text {mean }}\right) \text {, }}$

(2) Coefficient of variability (CV [\%]): SD/BP mean $\times 100$,

(3) Successive variation (SV):

$$
\sqrt{1 /(n-1) \quad \sum_{i=1}^{(n-1)}\left(\mathrm{BP}_{i}+1-\mathrm{BP}_{i}\right)^{2}}
$$

\section{Analysis of BPV}

SV was a continuous variable and was divided into four grades based on the quartiles. We assessed the relationship between SV and END and the 3-month outcome, as well as the relationship between each interval of SV and END and the 3-month outcome.

\section{Definition of SIASO}

The degree of stenosis was measured using MRI (the MRI parameters are detailed in our previous article [20]) by comparing the vessel diameter at the site of stenosis $\left(D_{\text {stenosis }}\right)$ with the normal vessel diameter distal to the stenosis $\left(D_{\text {distal }}\right)$ using the following formula: Stenosis $\%=\left(1-\left[D_{\text {stenosis }} / D_{\text {distal }}\right]\right) \times 100 \%[21]$.

SIASO was defined as no less than $50 \%$ stenosis of the intracranial artery that was responsible for the AIS [22].

\section{Outcome definition}

In our study the definition of END referred to neurological deterioration, with an increase in NIHSS score $\geq 4$ points in the first 72 hours after admission [23]. We followed up these patients and assessed their mRS scores at 90 days after onset. Favorable and poor outcomes were defined as $\mathrm{mRS} \leq 1$ and $\geq 2$, respectively. Incidents of stroke recurrence and death within the follow-up period were also recorded.

\section{Statistical analysis}


Statistical analyses were conducted using SPSS for Windows (v.20.0; IBM Corp., Armonk, NY, USA). Continuous variables with a normal distribution were reported as the mean $\pm S D$ and non-normally distributed variables as the median and interquartile range. Univariate analyses were performed using the $t$-test/Mann-Whitney $U$ test (for two groups) or one-way analysis of variance/Kruskal-Wallis $H$ test (for three or more groups) for continuous variables, and the $\chi^{2}$ test for categorical variables. Variables with $p<0.05$ in the univariate analysis were included in further binary multivariate logistic regressions. Statistical significance was defined as $p<0.05$ (two-sided). Statistical graphs were drawn using GraphPad Prism (v.9.0; GraphPad Software, San Diego, CA, USA).

\section{Results}

\section{Clinical characteristics of patients}

Of the 320 AIS patients who were treated with r-tPA IVT in our stroke unit, 210 patients were excluded for the following reasons: without SIASO ( $n=190)$, baseline $\mathrm{mRS} \geq 2(n=7)$, lost to follow-up $(n=7)$, underwent additional endovascular therapy $(n=4)$, and died as a result of non-ischemic stroke $(n=2)$. Therefore, 110 patients were enrolled in this study (Fig. 1).

These 110 patients had a mean age of $62.0 \pm 12.5$ years, and $86(78.2 \%)$ of the patients were male. Urapidil was used to lower BP in nine patients before IVT. Twenty patients (18.2\%) had END, while $37(33.6 \%)$ had a favorable outcome and $73(66.4 \%)$ had a poor outcome at the 3-month follow-up. There were significant differences among these four groups of SV quartiles in terms of age, hypertension, use of antihypertensive therapy before IVT, atrial fibrillation, and mRS score at 90 days (Table 1). There were no differences between the END and non-END groups in terms of age, atrial fibrillation, SBP on admission, onset-totreatment time, NIHSS on admission, or previous medical history (including hypertension, diabetes, hypercholesterolemia, history of coronary heart disease, previous stroke, and ex-smoker status; Table 2). Of the included patients, 23 (20.9\%) had atrial fibrillation. Compared with those with favorable outcomes, patients with poor outcomes were older, had higher NIHSS scores on admission, and were more likely to have atrial fibrillation. There were no differences in SBP on admission between the poor and favorable outcome groups (Table 2).

Table 1 Characteristics and successive blood pressure variability of the study sample 


\begin{tabular}{|c|c|c|c|c|c|c|}
\hline Characteristics & $\begin{array}{l}\text { All sample } \\
(n=110)\end{array}$ & $\begin{array}{l}\mathrm{SV}_{<25 \%<10.84} \\
(\mathrm{n}=27)\end{array}$ & $\begin{array}{l}\mathrm{SV}_{25 \%-50 \%}= \\
10.84-13.25 \\
(\mathrm{n}=28)\end{array}$ & $\begin{array}{l}S_{50 \%-75 \%}= \\
13.26-16.00 \\
(n=27)\end{array}$ & $\begin{array}{l}S V_{>75 \%}>16.00 \\
(n=28)\end{array}$ & $\begin{array}{l}\mathrm{P} \\
\text { value }\end{array}$ \\
\hline Age $^{\mathrm{a}}$ (years) & $62.0(12.5)$ & $55.4(13.4)$ & $60.2(14.1)$ & 67.7(8.7) & 64.7(9.8) & 0.004 \\
\hline Men $^{b}, \mathrm{n}(\%)$ & $86(78.2 \%)$ & $21(77.8 \%)$ & $23(82.1 \%)$ & $22(81.5 \%)$ & $20(71.4 \%)$ & 0.475 \\
\hline Hypertension $^{\mathrm{b}}, \mathrm{n}(\%)$ & $73(66.4 \%)$ & 16(59.3\%) & $16(57.1 \%)$ & 17(63.0\%) & $24(85.7 \%)$ & 0.026 \\
\hline $\begin{array}{l}\text { Use antihypertensive therapy } \\
\text { before IVT }{ }^{\mathrm{b}}, \mathrm{n}(\%)\end{array}$ & $9(8.2 \%)$ & $1(3.7 \%)$ & $1(3.6 \%)$ & 0 & $7(25.0 \%)$ & 0.002 \\
\hline Diabetes mellitus ${ }^{\mathrm{b}}, \mathrm{n}(\%)$ & $29(26.4 \%)$ & $4(14.8 \%)$ & $6(21.4 \%)$ & $9(33.3 \%)$ & $10(35.7 \%)$ & 0.472 \\
\hline $\begin{array}{l}\text { History of } \\
\text { hypercholesterolemia }^{\mathrm{b}}, \mathrm{n}(\%)\end{array}$ & $41(37.3 \%)$ & $7(25.9 \%)$ & $11(39.3 \%)$ & $11(40.7 \%)$ & $12(42.9 \%)$ & 0.787 \\
\hline Smokers/ex-smokers ${ }^{\mathrm{b}}, \mathrm{n}(\%)$ & $48(43.6 \%)$ & $11(40.7 \%)$ & $13(46.4 \%)$ & $9(33.3 \%)$ & $15(53.6 \%)$ & 0.082 \\
\hline Atrial fibrillation ${ }^{\mathrm{b}}, \mathrm{n}(\%)$ & $23(20.9 \%)$ & $3(11.1 \%)$ & $5(17.9 \%)$ & $6(22.2 \%)$ & $9(32.1 \%)$ & 0.006 \\
\hline $\begin{array}{l}\text { History of coronary heart } \\
\text { disease }^{\mathrm{b}}, \mathrm{n}(\%)\end{array}$ & $9(8.2 \%)$ & $1(3.7 \%)$ & $1(3.6 \%)$ & $5(18.5 \%)$ & $2(7.1 \%)$ & 0.705 \\
\hline Previous stroke ${ }^{\mathrm{b}}, \mathrm{n}(\%)$ & $23(20.9 \%)$ & $3(11.1 \%)$ & $4(14.3 \%)$ & $4(14.8 \%)$ & $12(42.9 \%)$ & 0.137 \\
\hline $\begin{array}{l}\text { Systolic blood pressure on } \\
\text { admission }^{\text {a }}\end{array}$ & $153.7(24.0)$ & $148.1(23.8)$ & $150.8(27.8)$ & $147.1(21.8)$ & $168.9(16.1)$ & 0.353 \\
\hline $\mathrm{OTT}^{\mathrm{a}}$ (minutes) & $194.2(54.8)$ & $183.0(55.2)$ & $181.1(52.7)$ & $215.9(47.8)$ & $197.3(58.4)$ & 0.067 \\
\hline $\begin{array}{l}\text { NIHSS on admission }{ }^{c}(\text { IQR,25- } \\
75)\end{array}$ & $\begin{array}{l}9.0(5.8- \\
14.0)\end{array}$ & $8.0(4.0-14.0)$ & $9.5(6.0-14.0)$ & $7.0(4.0-15.0)$ & $9.0(6.3-13.8)$ & 0.091 \\
\hline$E N D^{b}, n(\%)$ & $20(18.2 \%)$ & $2(7.4 \%)$ & $5(17.9 \%)$ & $4(14.8 \%)$ & $9(32.1 \%)$ & 0.320 \\
\hline $\mathrm{mRS}$ at 90 days ${ }^{\mathrm{c}}, \mathrm{n}(\%)$ & & & & & & 0.007 \\
\hline 0 & $20(18.2 \%)$ & $7(25.9 \%)$ & $4(14.3 \%)$ & $4(14.8 \%)$ & $5(17.9 \%)$ & \\
\hline 1 & $17(15.5 \%)$ & $6(22.2 \%)$ & $7(25.0 \%)$ & $2(7.4 \%)$ & $2(7.1 \%)$ & \\
\hline 2 & $21(19.1 \%)$ & $6(22.2 \%)$ & $1(3.6 \%)$ & $7(25.9 \%)$ & $7(25.0 \%)$ & \\
\hline 3 & $17(15.5 \%)$ & $3(11.1 \%)$ & $6(21.4 \%)$ & $4(14.8 \%)$ & $4(14.3 \%)$ & \\
\hline 4 & $19(17.3 \%)$ & $5(18.5 \%)$ & $6(21.4 \%)$ & $7(25.9 \%)$ & $1(3.6 \%)$ & \\
\hline 5 & $6(5.5 \%)$ & 0 & $2(7.1 \%)$ & $2(7.4 \%)$ & $2(7.1 \%)$ & \\
\hline 6 & $10(9.1 \%)$ & 0 & $2(7.1 \%)$ & 1(3.7\%) & $7(25.0 \%)$ & \\
\hline
\end{tabular}

Note: ${ }^{a}$ One-way ANOVA; ${ }^{b} \mathrm{x}^{2}$ test; ${ }^{\mathrm{C} K r u s k a l-W a l l i s ~} \mathrm{H}$ test.

SV Successive Variability of systolic blood pressure, NIHSS National Institutes of Health Stroke Scale, OTT Onset to Treatment Time, $m R S$ modified Rankin Scale, END Early Neurological Deterioration, IVT Intravenous Thrombolysis

\section{Association between BPV parameters and outcomes}

(1) Relationship between BPV parameters and END 
Although SV, SD, and CV all appeared to be lower in the END group than in the non-END group, there were no significant differences between the two groups (Table 2).

(2) Relationship between BPV parameters and 3-month outcomes

Compared with patients in the poor outcome group, SV and SD were significantly lower in the favorable outcome group (all $p<$ 0.05), while CV did not differ between the two groups (Table 2).

Table2 Risk factors of the 3-month poor outcome and END in univariable analysis

\begin{tabular}{|c|c|c|c|c|c|c|c|c|}
\hline & $\begin{array}{l}\text { Poor } \\
\text { outcome } \\
\text { (mRS=2-6) } \\
(n=73)\end{array}$ & $\begin{array}{l}\text { Favorable } \\
\text { outcome } \\
(\mathrm{mRS}=0-1) \\
(\mathrm{n}=37)\end{array}$ & $\begin{array}{l}\mathrm{t} / \mathrm{X}^{2} / \mathrm{z} \\
\text { Value }\end{array}$ & $P$ Value & $\begin{array}{l}\text { With END } \\
(n=20)\end{array}$ & $\begin{array}{l}\text { Without } \\
\text { END } \\
(n=90)\end{array}$ & $\begin{array}{l}\mathrm{t} / \mathrm{X}^{2} / \mathrm{z} \\
\text { Value }\end{array}$ & $P$ Value \\
\hline Age $^{\mathrm{a}}$ (years) & $64.8(10.9)$ & $56.7(13.8)$ & -3.129 & 0.003 & $64.8(10.3)$ & 61.43(12.9) & -1.077 & 0.284 \\
\hline $\mathrm{Men}^{\mathrm{b}}, \mathrm{n}(\%)$ & $12(16.4 \%)$ & $12(32.4 \%)$ & 3.682 & 0.055 & $17(85.0 \%)$ & $69(76.7 \%)$ & 0.666 & 0.556 \\
\hline Hypertension $^{\mathrm{b}}, \mathrm{n}(\%)$ & $51(69.9 \%)$ & $22(59.5 \%)$ & 1.191 & 0.275 & 17(85.0\%) & $56(62.2 \%)$ & 3.803 & 0.067 \\
\hline $\begin{array}{l}\text { Use antihypertensive } \\
\text { therapy before } \mathrm{IVT}^{\mathrm{b}}, \mathrm{n} \\
(\%)\end{array}$ & $7(9.6 \%)$ & $2(5.4 \%)$ & 0.572 & 0.715 & $4(20.0 \%)$ & $5(5.6 \%)$ & 4.545 & 0.055 \\
\hline $\begin{array}{l}\text { Diabetes mellitus }{ }^{\mathrm{b}}, \mathrm{n} \\
(\%)\end{array}$ & $21(28.8 \%)$ & $8(21.6 \%)$ & 0.646 & 0.422 & $6(30.0 \%)$ & $23(25.6 \%)$ & 0.167 & 0.683 \\
\hline $\begin{array}{l}\text { History of } \\
\text { hypercholesterolemiab } \\
\mathrm{n}(\%)\end{array}$ & $25(34.7 \%)$ & $16(43.2 \%)$ & 0.756 & 0.385 & $6(68.4 \%)$ & $35(61.1 \%)$ & 0.357 & 0.550 \\
\hline $\begin{array}{l}\text { Smokers/ex-smokers }{ }^{\mathrm{b}} \\
\mathrm{n}(\%)\end{array}$ & $31(42.5 \%)$ & $17(45.9 \%)$ & 0.121 & 0.728 & $11(55.0 \%)$ & $37(41.1 \%)$ & 1.283 & 0.257 \\
\hline $\begin{array}{l}\text { Atrial fibrillation }{ }^{\mathrm{b}}, \mathrm{n} \\
(\%)\end{array}$ & $20(27.4 \%)$ & $3(8.1 \%)$ & 5.525 & 0.024 & $6(30.0 \%)$ & $17(18.9 \%)$ & 1.222 & 0.269 \\
\hline $\begin{array}{l}\text { History of coronary } \\
\text { heart disease }{ }^{b}, \mathrm{n}(\%)\end{array}$ & $8(11.0 \%)$ & $1(2.7 \%)$ & 2.228 & 0.268 & $2(10.0 \%)$ & $7(7.8 \%)$ & 0.108 & 0.666 \\
\hline Previous stroke $^{\mathrm{b}}, \mathrm{n}(\%)$ & $19(26.1 \%)$ & $4(10.8 \%)$ & 3.438 & 0.083 & $6(30.0 \%)$ & 17(18.9\%) & 1.222 & 0.269 \\
\hline $\begin{array}{l}\text { Systolic blood } \\
\text { pressure on } \\
\text { admission }^{a}\end{array}$ & 153.7(24.4) & $153.2(24.2)$ & -0.108 & 0.914 & $161.2(25.6)$ & 151.9(23.7) & -1.488 & 0.140 \\
\hline $\mathrm{OTT}^{\mathrm{a}}$ (minutes) & $201(49.8)$ & $180.9(62.0)$ & -1.842 & 0.068 & $193.0(56.8)$ & 194.5(54.6) & 0.115 & 0.909 \\
\hline $\begin{array}{l}\text { NIHSS on admissionc } \\
(\text { IQR, 25-75) }\end{array}$ & $\begin{array}{l}11.0(7.0- \\
16.0)\end{array}$ & $6.0(3.5-9.0)$ & -4.377 & 0.000 & $\begin{array}{l}10(5.3- \\
16.3)\end{array}$ & $9(5.8-14.0)$ & -0.641 & 0.522 \\
\hline$S^{a}$ & $14.5(4.3)$ & $11.8(3.2)$ & -3.650 & 0.000 & $15.2(4.3)$ & $13.2(4.0)$ & -1.972 & 0.051 \\
\hline$S D^{a}$ & $12.7(3.8)$ & 10.9(3.3) & -2.569 & 0.012 & $13.7(4.8)$ & $11.7(3.4)$ & -1.751 & 0.093 \\
\hline $\mathrm{CV}^{\mathrm{a}}$ & $8.9(2.6)$ & $8.0(2.4)$ & -3.650 & 0.092 & $9.2(3.2)$ & $8.5(2.4)$ & -1.165 & 0.247 \\
\hline
\end{tabular}

Note: ${ }^{a}$ Mean(SD),t-test; ${ }^{b} \mathrm{n}(\%)$, chi-square test; ${ }^{\mathrm{c}}$ Mann-Whiteny Utest. 
mRS modified Rankin Scale, NIHSS National Institutes of Health Stroke Scale, OTT Onset to Treatment Time, END Early Neurological Deterioration,

SV Successive Variation of systolic blood pressure, SD Standard Deviation of systolic blood pressure, CV Coefficient of systolic blood pressure Variation

Independent variables that were significantly different between the favorable and poor outcome groups in the univariable analysis were then entered into the subsequent logistic regression models (Table 3). In Model 1, age, NIHSS score on admission, atrial fibrillation, SD, and overall SV were entered using a backward Wald method. NIHSS score on admission (odds ratio [OR] = $1.206,95 \%$ confidence interval $[\mathrm{Cl}]=1.084-1.342, p=0.001)$ and overall SV $(\mathrm{OR}=1.182,95 \% \mathrm{Cl}=1.035-1.348, p=0.013)$ were significantly associated with poor outcome at 3 months. In Model 2, patients were divided into four groups based on systolic SV value quartiles $\left(\mathrm{SV}_{<25 \%}<10.84, \mathrm{SV}_{25 \%-50 \%}=10.84-13.25, \mathrm{SV}_{50 \%-75 \%}=13.26-16.00\right.$ and $\left.\mathrm{SV}_{>75 \%}>16.00\right)$, and these were entered into the model along with the other variables used in Model 1. NIHSS score on admission $(\mathrm{OR}=1.227,95 \% \mathrm{Cl}=1.099-$ $1.369, p<0.001), \mathrm{SV}_{50 \%-75 \%}\left(\mathrm{SV}_{<25 \%}\right.$ as reference; $\left.\mathrm{OR}=4.449,95 \% \mathrm{Cl}=1.231-16.075, p=0.023\right)$, and $\mathrm{SV}_{>75 \%}\left(\mathrm{SV}_{<25 \%}\right.$ as reference; $\mathrm{OR}=8.676,95 \% \mathrm{Cl}=1.892-39.775, p=0.005$ ) were significant predictors of poor outcome at 3 months (Table 3$)$. The $\mathrm{mRS}$ score distribution according to SV quartiles is shown in Fig. 2.

Table3 Multivariate logistic regression of risk factors for 3-month poor outcome.

\begin{tabular}{|c|c|c|c|}
\hline \multirow[t]{2}{*}{ Variable } & \multicolumn{3}{|c|}{ 3-month } \\
\hline & $\beta$ & $O R \otimes 95 \% C l]$ & $P$ value \\
\hline \multicolumn{4}{|l|}{ Model $^{1}$} \\
\hline Age & 0.038 & $1.038(0.998-1.081)$ & 0.064 \\
\hline NIHSS on admission & 0.187 & $1.206(1.084-1.342)$ & 0.001 \\
\hline Atrial fibrillation & 0.204 & $1.227(0.278-5.403)$ & 0.787 \\
\hline SV & 0.167 & $1.182(1.035-1.348)$ & 0.013 \\
\hline SD & -0.048 & $0.954(0.780-1.166)$ & 0.643 \\
\hline \multicolumn{4}{|l|}{ Model $^{2}$} \\
\hline Age & 0.033 & $1.033(0.992-1.076)$ & 0.114 \\
\hline NIHSS on admission & 0.204 & $1.227(1.099-1.369)$ & 0.000 \\
\hline Atrial fibrillation & -0.007 & $0.993(0.218-4.520)$ & 0.993 \\
\hline SD & 0.005 & $1.005(0.855-1.1810)$ & 0.951 \\
\hline $\mathrm{SV}\left(\mathrm{SV}_{<25 \%}\right.$ as reference) & & & 0.013 \\
\hline $\mathrm{SV}_{25 \%-50 \%}$ & 0.766 & $2.152(0.650-7.128)$ & 0.210 \\
\hline $\mathrm{SV}_{50 \%-75 \%}$ & 1.493 & $4.449(1.231-16.075)$ & 0.023 \\
\hline$S V_{>75 \%}$ & 2.161 & $8.676(1.892-39.775)$ & 0.005 \\
\hline
\end{tabular}

SV Successive Variation of systolic blood pressure; $S D$ Standard Deviation of systolic blood pressure 1 With overall SV entered.

2 With categorized SV entered

Discussion

In the present study, higher systolic SV was associated with poorer 3-month outcomes in patients with SIASO who were treated with IVT. An increase in systolic SV may thus predict a higher risk of poor outcome at 3 months $\left(\mathrm{SV}_{50 \%-75 \%}[\mathrm{OR}=4.449,95 \% \mathrm{Cl}=1.231-\right.$ $16.075, p=0.023], \mathrm{SV}_{>75 \%}[\mathrm{OR}=8.676,95 \% \mathrm{Cl}=1.892-$ $39.775, p=0.005])$. However, there was no clear relationship between systolic SV and END. Our findings may help physicians to identify patients with a relatively high risk of poor outcome at 3 months.

SV is an important index of BPV, and in our study it was associated with 3-month outcomes in AIS patients after IVT; this is consistent with the results of two previous studies $[17,24]$. A study by Mei Yong et al. [24] in the European Cooperative Acute Stroke Study II trial revealed that high SBP variability is associated with poor outcome. Furthermore, an analysis from the Third International Stroke Trial (IST-3) reported an association between higher BPV and adverse events, the occurrence of symptomatic intracranial hemorrhage, and poor 6-month outcomes [17]. However, none of these studies focused on patients with SIASO, and the IST-3 study only measured BP at three timepoints after IVT, while we measured BP hourly for at least 24 hours after IVT. Thus, the BPV in our study was likely more accurate than in other studies that measured BP less frequently. 
The mechanism underlying the negative correlation between BPV and prognosis after IVT remains uncertain. Recent studies have reported that many patients have autonomic dysfunction after ischemic stroke [25-27]. BP fluctuation is a manifestation of autonomic dysfunction. During the early stage of ischemic stroke, a rapid increase in BP may cause intracranial pressure to rise and edema or bleeding to occur at the infarction site, which can lead to death or poor functional outcome [28]. However, a large decrease in BP may lead to low perfusion in the infarct area; this effect might be much clearer in AIS patients with largeartery stenosis because patients with SIASO are very sensitive to BP fluctuations, especially in the first few hours after AIS [28, 29].

Cerebral autoregulation (CA) is the ability of the brain to regulate its own blood supply, which maintains an adequate and stable cerebral blood flow despite changes in cerebral perfusion pressure. However, CA is impaired after ischemic stroke, and this autoregulation is damaged in patients with intracranial arterial stenosis; furthermore, patients with more severe stenosis tend to have more severe dysautoregulation [30]. One study reported that CA impairment ipsilateral to the AIS is associated with a larger infarction and poorer clinical outcome compared with patients with unimpaired CA ipsilateral to the AIS [30]. With CA impairment, BP fluctuations have an important effect on cerebral blood flow. Moreover, when BPV increases to levels beyond the regulation of $\mathrm{CA}$, it can lead to hypoperfusion or hyperperfusion in the infarction area.

Ischemic stroke is a clinical syndrome with a varied pathogenesis, including aortic atherosclerosis, small arterial occlusion, and cardiogenic embolism. BP fluctuations have different effects on ischemic stroke caused by different mechanisms [30]. In China, $33-55 \%$ of ischemic stroke is caused by intracranial arterial stenosis or occlusion [30], and the prognosis of patients with this type of stroke is poorer than cerebral infarction with small vessel occlusion. BPV may be an indicator for risk stratification in this group of patients. In the present study, high SV in the early stage after IVT among patients with SIASO increased the risk of poor outcome at 3 months. This finding may help physicians to screen the most high-risk patients with poor prognosis from other high-risk patients at the early stage of AIS, and thus provide more appropriate interventions. However, we did not find any correlation between SV and END. Previous studies by other researchers have also failed to find a link between short-term outcomes (2-week outcome and in-hospital outcome), during the acute phase of ischemic stroke, and BPV [11, 32, 33].

SV, SD, and CV are three different indexes of BPV. In our study, there was only a relationship between SV and the 3-month outcome, while SD and CV were not associated with this outcome. Notably, SV is more commonly used in studies because it better reflects the time-series variability of BP. In contrast, SD and CV ignore temporal changes in the data, which can result in the same SD or CV in individuals with different clinical characteristics [34].

There were several strengths to our study. First, BPV was calculated by recording hourly BP within 24 hours after thrombolysis, which was far more frequently than in other studies and led to more accurate BPV results [11, 14]. Second, to the best of our knowledge, ours was one of the few studies to have focused on AIS patients after IVT and consider the effects of SAISO on prognosis. However, there were also several limitations in our study. First, the sample size was relatively small. Second, our study was a retrospective study. Third, magnetic resonance angiography was used to evaluate arterial stenosis in this study; however, this method is not as accurate as digital subtraction angiography for evaluating arterial stenosis, and might overestimate SIASO.

Finally, intermittent cuff measurement was used to monitor BP in the present study, while continuous cuff monitoring or invasive arterial BP are more accurate.

\section{Conclusions}

Systolic SV had a negative relationship with 3-month outcome in AIS patients with SIASO who were treated with IVT, which indicates that BPV may affect the outcome of AIS. Further multi-center prospective studies with larger sample sizes are warranted.

\section{Abbreviations}

IVT: Intravenous thrombolysis therapy; TOAST: Trial of Org 10172 in Acute Stroke Treatment; NIHSS: National Institutes of Health Stroke Scale; SBP: Systolic blood pressure; SIASO: Symptomatic intracranial arterial stenosis or occlusion; AIS: Acute ischemic stroke; BPV: Blood pressure variability; BP: Blood pressure; rt-PA: recombinant tissue plasminogen activator; MRI: 
Magnetic resonance imaging; mRS: modified Rankin Scale; SD: Standard deviation of mean BP; CV: Coefficient of variability; SV: Successive variation; CA: Cerebral autoregulation.

\section{Declarations}

\section{Acknowledgments}

Not applicable.

\section{Authors' contributions}

YKC and LYL designed the work and analyzed the data. MXY, DHQ and HPY collected the clinical data. MXY and LYL wrote the manuscript. MXY and JHZ wrote the diagrams. All authors read and approved the final manuscript; contributed toward data analysis, drafted and revised the paper, and agreed to be accountable for all aspects of the work.

\section{Funding}

This study was funded by the Medical Scientific Research Foundation of Guangdong Province, China, Grant/Award (Number: A2018322). The funding body had no role in the design of the study, collection, analysis, and interpretation of the data, and in writing of the manuscript.

\section{Availability of data and materials}

The datasets generated and/or analyzed during the current study are not publicly available because they are personal data, but they are available from the corresponding author on reasonable request. Ethics approval and consent to participate This study protocol was approved by the Ethics Committee of Dongguan People's Hospital. As this was a retrospective study, consent to participate was waived.

\section{Consent for publication}

As this was a retrospective study, consent for publication was waived.

\section{Competing interests}

The authors declare that they have no competing interests.

\section{References}

1. Lozano R, Naghavi M, Foreman K, et al. Global and regional mortality from 235 causes of death for 20 age groups in 1990 and 2010: A systematic analysis for the global burden of disease study 2010. Lancet. 2012;380:2095-2128.

2. Murray CJ, Vos T, Lozano R, et al. Disability-adjusted life years (DALYs) for 291 diseases and injuries in 21 regions, 19902010: A systematic analysis for the global burden of disease study 2010. Lancet. 2012; 380:2197-2223.

3. Liu Y, Xiao W, Lu J, et al. Asymmetrical cortical vessel sign predicts prognosis after acute ischemic stroke. Brain and Behavior. 2020;10(7).

4. Marler JR, Tilley BC, Lu M, et al. Early stroke treatment associated with better outcome: The NINDS rt-PA stroke study. Neurology. 2000;55:1649-1655.

5. Lees KR, Bluhmki E, von Kummer R, et al. Time to treatment with intravenous alteplase and outcome in stroke: An updated pooled analysis of ECASS, ATLANTIS, NINDS, and EPITHET trials. The Lancet. 2010; 375:1695-1703.

6. Broderick JP, Phillips SJ, O'Fallon WM, Frye RL and Whisnant JP. Relationship of cardiac disease to stroke occurrence, recurrence, and mortality. Stroke. 1992;23:1250-1256.

7. Thanvi B, Treadwell S, Robinson T. Early neurological deterioration in acute ischaemic stroke: predictors, mechanisms and management. Postgrad Med J. 2008;84:412-7. 
8. Simonsen CZ, Schmitz ML, Madsen MH, et al. Early neurological deterioration after thrombolysis: clinical and imaging predictors. Int J Stroke. 2016;11:776-82.

9. Kim JM, Moon J, Ahn SW, et al. The etiologies of early neurological deterioration after thrombolysis and risk factors of ischemia progression. J Stroke Cerebrovasc Dis. 2016;25:383-8.

10. Ray BK, Hazra A, Ghosal M, et al. Early and delayed fatality of stroke in Kolkata, India: Results from a 7-year longitudinal population-based study. J Stroke Cerebrovasc Dis. 2013;22:281-289.

11. Kellert, Lars, Hametner, Christian, Ahmed, \& Niaz, et al. Reciprocal Interaction of 24-Hour Blood Pressure Variability and Systolic Blood Pressure on Outcome in Stroke Thrombolysis.

12. Bolanle M. Famakin, MD; Marc I. Chimowitz, MBChB; Michael J. Lynn, MS; et al. Causes and Severity of Ischemic Stroke in Patients With Symptomatic Intracranial Arterial Stenosis. Stroke. 2009;40:1999-2003.

13. Barnett HJ, Gunton RW, Eliasziw M, et al. Causes and severity of ischemic stroke in patients with internal carotid artery stenosis. JAMA. 2000;283:1429 -1436.

14. Endo K, Kario K, Koga M, et al. Impact of Early Blood Pressure Variability on Stroke Outcomes After Thrombolysis The SAMURAI rt-PA Registry. Stroke. 2013;44(3):816-818.

15. Kellert L, Sykora M, Gumbinger C, Herrmann O, \& Ringleb PA. Blood pressure variability after intravenous thrombolysis in acute stroke does not predict intracerebral hemorrhage but poor outcome. Cerebrovascular Diseases. 2021;33(2):135-140.

16. Castillo J, Leira R, García MM, Serena J, Blanco M, Dávalos A. Blood pressure decrease during the acute phase of ischemic stroke is associated with brain injury and poor stroke outcome. Stroke. 2004;35:520-526.

17. Berge E, Cohen G, Lindley RI, Sandercock P, Wardlaw JM, Sandset EC, et al. Effects of blood pressure and blood pressurelowering treatment during the first 24 hours among patients in the Third International Stroke Trial of Thrombolytic treatment for acute ischemic stroke. Stroke. 2015;46:3362-3369.

18. Adams Jr HP, Bendixen BH, Kappelle LJ, et al. Classification of subtype of acute ischemic stroke. Definitions for use in a multicenter clinical trial. TOAST. Trial of Org 10172 in Acute Stroke Treatment. Stroke. 1993;24, 35-41.

19. Shinohara Y, Yanagihara T, Abe K, Yoshimine T, Fujinaka T, Chuma T, et al. II. Cerebral infarction/transient ischemic attack (TIA). J StrokeCerebrovasc Dis. 2011;20(Suppl 4):S31-S73.

20. Liu YL, Yin HP, Qiu DH, et al. Multiple hypointense vessels on susceptibility-weighted imaging predict early neurological deterioration in acute ischaemic stroke patients with severe intracranial large artery stenosis or occlusion receiving intravenous thrombolysis. Stroke and Vascular Neurology. 2020.

21. North American Symptomatic Carotid Endarterectomy Trial Collaborators. Beneficial effect of carotid endarterectomy in symptomatic patients with high grade carotid stenosis. N Engl J Med. 1991;325:445-453.

22. Chimowitz M I, Strong J, Brown MB, et al. Prognosis of Patients With Symptomatic Vertebral or Basilar Artery Stenosis. Stroke. 1998; 29(7):1389-1392.

23. Siegler JE, Schild SM. Early Neurological seterioration (END) after stroke: the END depends on the definition. Int J Stroke. 2011;6(3):211-2.

24. Yong $\mathrm{M}$, and Kaste M. Association of characteristics of blood pressure profiles and stroke outcomes in the ECASS-II trial. Stroke. 2008;39:366-372.

25. Tang SJ, Li X, Fan YH, et al. Stroke Outcome Prediction by Blood Pressure Variability, Heart Rate Variability, and Baroreflex Sensitivity. Stroke. 2020;51:00-00.

26. Dütsch M, Burger M, Dörfler C, Schwab S, Hilz MJ. Cardiovascular autonomic function in poststroke patients. Neurology. 2007;69:2249-2255.

27. Li X, Ge T, Howan L, et al. Autonomic Dysfunction Predicts Clinical Outcomes After Acute Ischemic Stroke A Prospective Observational Study. Stroke. 2018;49:00-00

28. Ko Y, Park JH, Yang MH, et al. The significance of blood pressure variability for the development of hemorrhagic transformation in acute ischemic stroke. Stroke. 2010;41(11):2512-8.

29. Powers WJ. Acute hypertension after stroke: the scientific basis for treatment decisions. Neurology. 1993;43:461- 467. 
30. Chen J, Liu J, Xu WH, et a1. impaired dynamic cerebral autoregulation and cerebrovascular reactivity in middle cerebral artery stenosis. PloSone. 2014;9(2):e88232】

31. Aoi MC, Hu K, Mt L, et al. Impaired cerebral autoregulation is associated with brain atrophy and worse functional status in chronic ischemic stroke. PLoS One. 2012;7:e46794.

32. Tziomalos K, Giampatzis V, Bouziana SD, Spanou M, Kostaki S, Papadopoulou M, et al. No association observed between blood pressure variability during the acute phase of ischemic stroke and in-hospital outcomes. Am J Hypertens. 2016;29:841-846.

33. Manning LS, Mistri AK, Potter J, Rothwell PM, Robinson TG. Short-term blood pressure variability in acute stroke: post hoc analysis of the controlling hypertension and hypotension immediately post stroke and continue or stop post-stroke antihypertensives collaborative study trials. Stroke. 2015;46:1518-1524.

34. Xu B, Ji Q, Zhang Y, Shen L, Cao M, Cai K. Postoperative blood pressure variability exerts an influence on clinical outcome after coil embolization of ruptured intracranial aneurysms. Neurol Res. 2017;39(9):813-8.

\section{Figures}

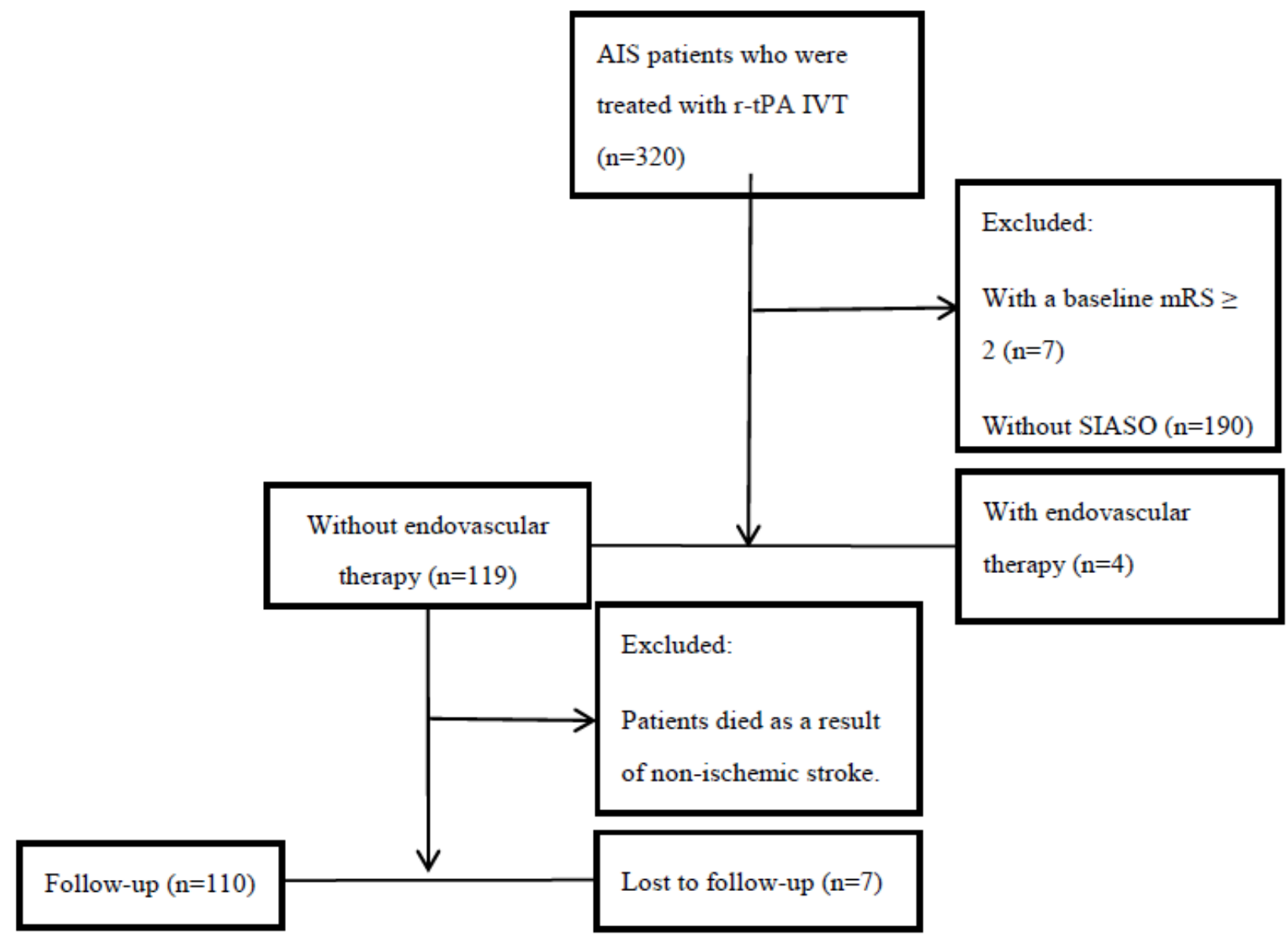

\section{Figure 1}

Flowchart of the selection process. AIS Acute Ischemic Stroke, IVT Intravenous Thrombolysis, mRS modified Rankin Scale, SIASO Symptomatic Intracranial Arterial Stenosis or Occlusion 


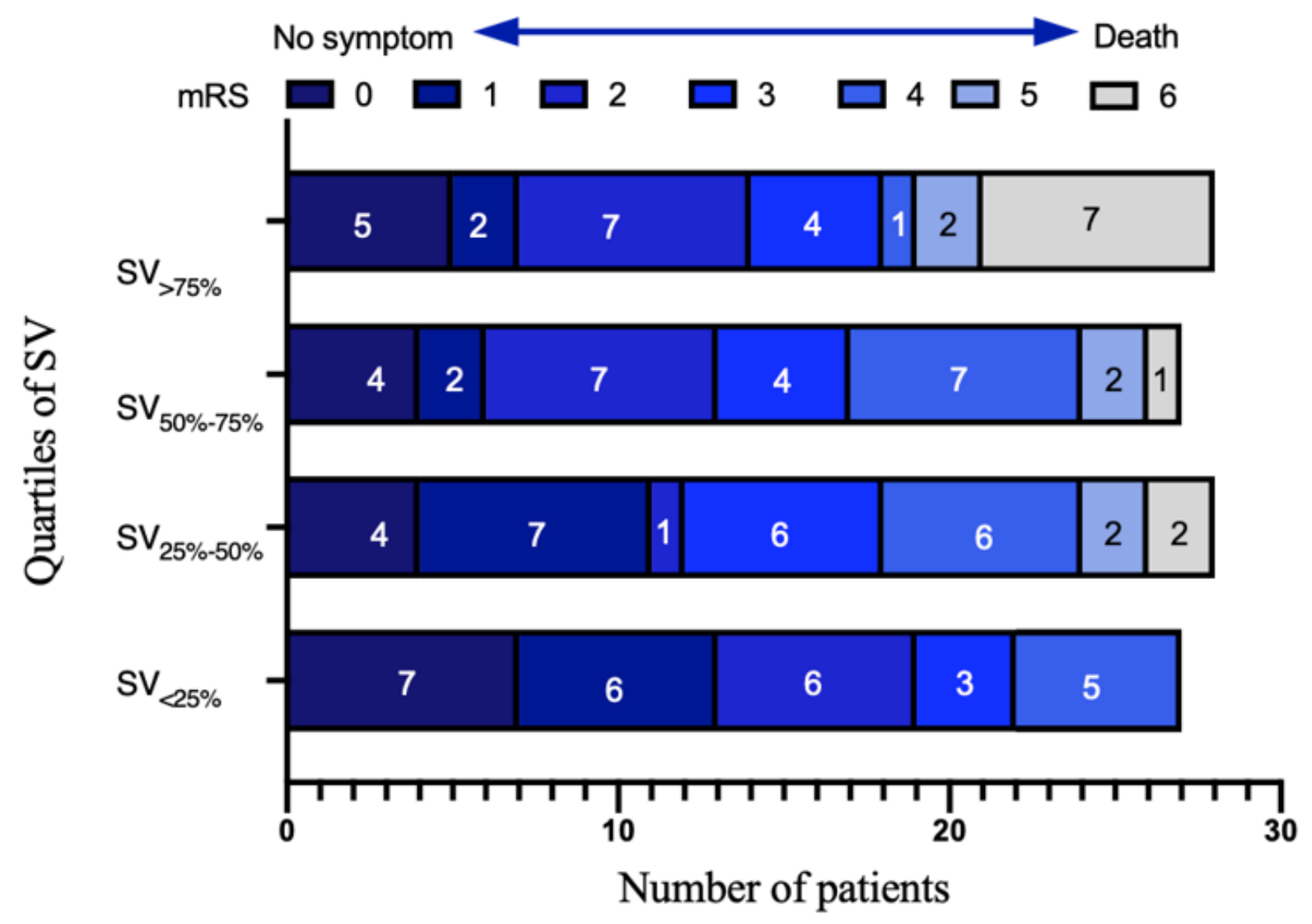

Figure 2

Modified Rankin Scale scores distribution according to quartiles of systolic SV 